\title{
Growth rate and TRI5 gene expression profiles of Fusarium equiseti strains isolated from Spanish cereals cultivated on wheat and barley media at different environmental conditions
}

\author{
Patricia Marin , Miguel Jurado , M. Teresa González-Jaén
}

\begin{abstract}
A B S T R A C T
Fusarium equiseti is a toxigenic spedes that often contaminates cereal crops from diverse climatic regions such as Northern and Southern Europe. Previous results suggested the existence of two distinct populations within this species with differences in toxin profile which largely corresponded to North and South Europe (Spain). In this work, growth rate profiles of $4 \mathrm{~F}$ equiseti strains isolated from different cereals and distinct Spanish regions were determined on wheat and barley based media at a range of temperatures $(15,20,25,30,35$ and $40 \mathrm{t})$ and water potential regimens (- $0.7,-2.8,-7.0$, and $-9.8 \mathrm{MPa}$, corresponding to $0.99,0.98,0.95$ and $0.93 \mathrm{a}_{\mathrm{w}}$ values). Growth was observed at all temperatures except at $40{ }^{\circ} \mathrm{C}$, and at all the solute potential values except at $-9.8 \mathrm{MRa}$ when combined with $15^{\circ} \mathrm{C}$. Optimal growth was observed at 20-30 "Cand $-0.7 /-2.8 \mathrm{MPa}$ The effect of these factors on trichothecene biosynthesis was examined on a $\mathrm{F}$ equiseti strain using a newly developed real time RT-PCR protocol to quantify TRI5 gene expression at 15,25 and $35^{\circ} \mathrm{C}$ and $-0.7,-2.8,-7.0$ and $-9.8 \mathrm{MPa}$ on wheat and barley based media. Induction of TRI5 expression was detected between 25 and $35^{\circ} \mathrm{C}$ and -0.7 and $-2.8 \mathrm{MPa}$, with maximum values at $35^{\circ} \mathrm{C}$ and $-2.8 \mathrm{MPa}$ being higher in barley than in wheat medium. These results appeared to be consistent with a population well adapted to the present climatic conditions and predicted scenarios for Southern Europe and suggested some differences depending on the cereal considered. These are also discussed in relation to other Fusarium species co-occurring in cereals grown in this region and to their significance for prediction and control strategies of toxigenic risk in future scenarios of climate change for this region.
\end{abstract}

\section{Introduction}

Fusarium equiseti (Corda) Saccardo is a cosmopolitan fungus distributed across regions with cool through to hot and arid climates (Leslie and Summerell, 2006). It behaves as a soil saprophyte associated with rotting fruit and other decaying plant material, and as a pathogen of a wide range of crops. These include cereals, wheat, triticale, maize, oat and rice, participating as a minor component of the Fusarium head blight (FHB) disease complex (Kosiak et al., 2003; Logrieco et al., 2003; Xu et al., 2008). Other susceptible crops are asparagus, cotton, potato, tomato, cowpea, onion, bean, bush bean, broad bean, chickpea, pea, alfalfa, canola, kohlrabi, melon and ginseng (Palmero et al., 2011; Punja et al., 2008). Besides cultivated plants, it also colonizes wild species, including herbal plants and trees, e.g. Equisetum L, Chenopodium L and Pinus L (Goswami et al., 2008). AlthoughF. equiseti is considered as a moderately aggressive pathogen for these plants, it might also become a long-term root endophyte with beneficial effects for other host plants, such as protecting them against other phytopathogenic fungi (Macia-
Vicente et al., 2009). Additionally, F. equiseti is reported to produce a vast range of toxic secondary metabolites such as A and B trichothecenes, and others such as butenolide, beauvericin (BEA), equisetine (EQJ, fusarochromanone (FUSCHR) and zearalenone (ZEA) (Adejumo et al., 2007; Kosiak et al., 2005; Leslie and Summerell, 2006; Marin et al., 2012). Trichothecenes are potent inhibitors of protein synthesis in eukaryotic cells (Brown et al., 2001). They cause different acute and severe diseases in humans and animals depending on the type of trichothecene ingested (Trenholm et al., 1989). Accordingly, their presence in foods and feeds is under legal regulation.

The phylogenetic status of this species is far from being elucidated. This represents a crucial issue in determining the risk that this species poses both as a pathogen and as a mycotoxin producer. $F$. equiseti is included in the so-called Fusarium incarnatum- $F$. equiseti species complex (FIESC) based on phylogenetic studies using a multilocus DNA sequence approach. This complex is a highly diverse group which may contain several genetically isolated populations or cryptic species (ODonnelletal., 2009,2012). This species frequently contaminates cereals in Northern and Southern Europe in spite of highly differing climatic characteristics ofthese regions (Jurado et al., 2006; Kosiak et al., 2005; Logrieco et al., 2003; Marin, 2010; Soldevilla 

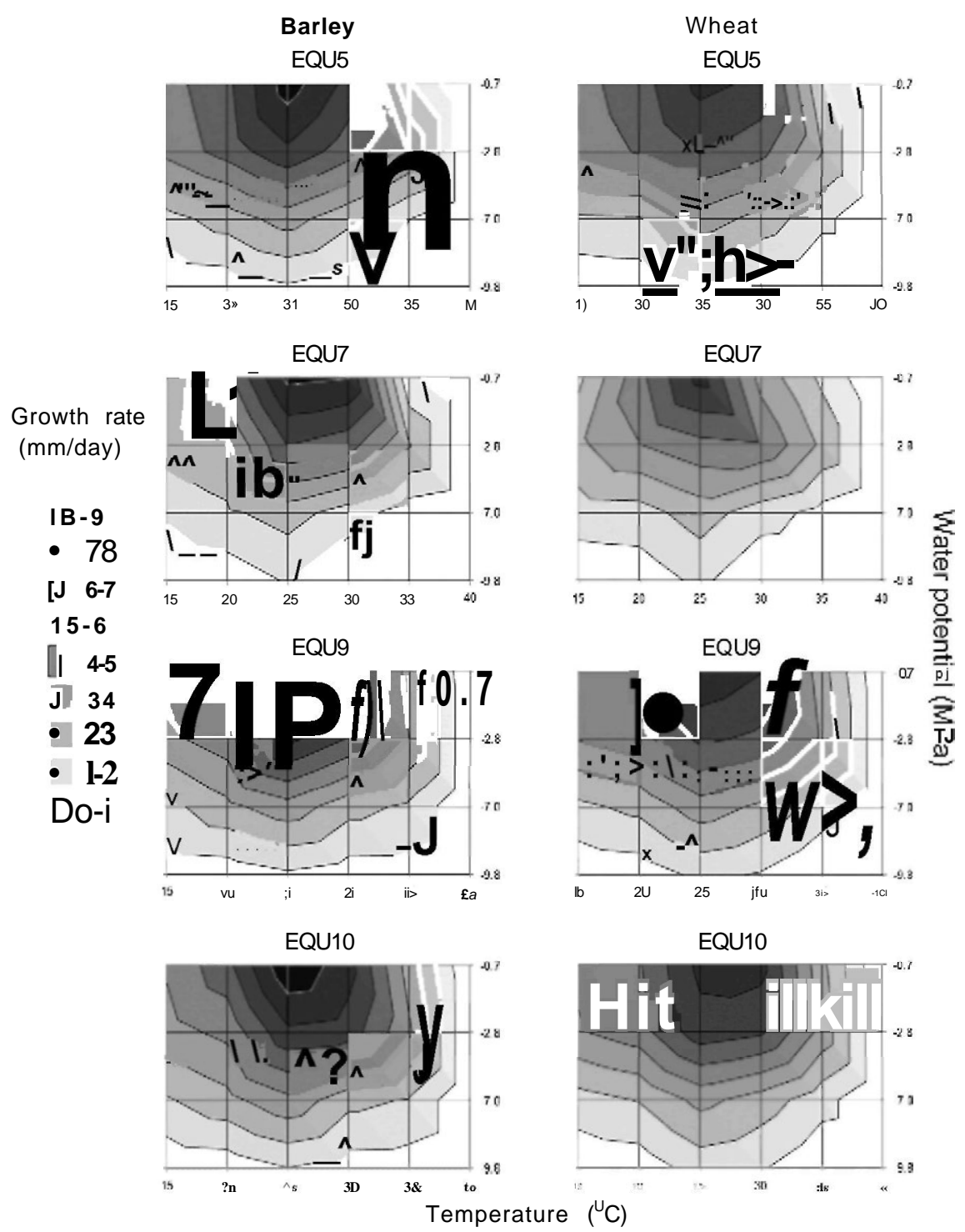

EQU10

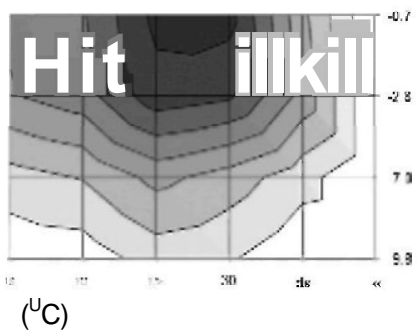

Fig. 1. Bi-dimensional maps of relative growth rate of the four $F$. equiseti strains on barley and wheat in response to water potentials and temperatures.

et al., 2005; Stepien et al., 2012). Subsequent studies indicated that the Northern and Southern European $F$. equiseti strains are separated largely into two phylogenetically distinct clusters (Jurado et al., 2006; Marin et al., 2012), which basically correspond to FIESC-14 (F. equiseti sensu stricto) and F IESC-5c, respectively. F. equiseti strains from F IESC-5 group were also reported in Italy (Balmas et al., 2010) and in a recent study carried out in Spain (Castella' and Cabanes, 2014). Moreover, strains isolated from Spain showed a different mycotoxin profile (Marin et al., 2012) to that previously described for strains from Northern Europe (Kosiak et al., 2005). These reports indicating the existence of distinct populations within this species might also indicate the existence of ecophysiological differences between them.

Temperature and water potential are major environmental factors affecting fungal growth and mycotoxin biosynthesis. Previous studies have shown that the patterns of fungal growth and toxin biosynthesis in the pathogenic and mycotoxigenic Fusarium verticillioid.es, Fusarium proliferation and Fusarium graminearum are consistent with their occurrence within Europe and especially in Spanish cereal fields (Jurado et al., 2008; Marin et al., 2010a, 2010b). The effect of water potential and temperature on fungal growth, trichothecene production and pathogenicity was reported previously (Kosiak et al., 2005; Marin et al., 2012; Palmero et al., 2011). However, there are no studies that link these data at a fundamental level to expression of key regulatory genes such as TRI5 in the case off. equiseti. TRI5 is the key gene of trichothecene biosynthesis and encodes trichodiene synthase, which catalyzes the first step in the trichothecene biosynthetic pathway, the isomerisation and cyclation of farnesil pyrophosphate to trichodiene (Foroud and Eudes, 2009). Previous studies reported that the expression of key genes of mycotoxin biosynthetic pathways, such as FUM1 or TRI5, measured by real time RT-PCR is positively related to production of fumonisin and trichothecenes in $F$. verticillioid.es or $F$. proliferation and $F$. graminearum, respectively (Doohan et al., 1999; Jurado et al., 2010; Lopez-Errasquin et al., 2007). These and related approaches were useful to unravel the influence of environmental factors on regulation of toxin biosynthesis in a number of species and toxins and to develop models to predict toxin risk (Marin et al., 2010a, 2010b; Schmidt-Heydt et al., 2011).

The objectives of this study were to examine the effects of interacting conditions of temperature, water potential and substrates (wheat and barley) on (i) growth and (ii) expression of the trichothecene biosynthetic TRB gene using a newly developed protocol of real time RT-PCR for $F$. equiseti. The results are compared and discussed in relation to other Fusarium species co-occurring in cereals grown in Spain and to 
Table 1

Multifactorial ANOVA (strain/* ${ }_{w} /$ temperature) of growth rates of the four $\mathrm{F}$ equiseti strains EQU5, EQU7, EQU9 and EQU10 F equiseti strains incubated with two substrates (barley or wheat) for 10 days at different temperatures $\left(15,20,25,30,35\right.$ and $40{ }^{\circ} \mathrm{C}$ ) and water potentials $(-0.7,-2.8,-7.0$ and $-9.8 \mathrm{MPa}$ ) and multifactorial ANOVA (substrate/* ${ }_{\mathrm{w}} /$ temperature) for EQU9 (similar results were obtained for the other 3 strains).

\begin{tabular}{|c|c|c|c|}
\hline variation & df & Mean square & $\mathrm{F}^{*}$ \\
\hline \multicolumn{4}{|l|}{ Barley } \\
\hline Strain & 3 & 38.879 & $11.432^{* * * *}$ \\
\hline${ }^{2}{ }^{2}{ }_{w}$ & 3 & 1381.043 & $29.990^{* * *}$ \\
\hline Temperature & 4 & 280.703 & $5.941^{* *}$ \\
\hline Strain $\mathrm{x} * *$ & 9 & 3.452 & 1.566 \\
\hline Strain $\mathrm{x}$ temperature & 12 & 3.401 & 1.543 \\
\hline${ }^{\wedge} \mathrm{W} \times$ temperature & 12 & 46.050 & $20.897^{* * *}$ \\
\hline Strain $\mathrm{x} * P, \mathrm{x}$ temperature & 36 & 2.204 & $10.091^{* * *}$ \\
\hline \multicolumn{4}{|l|}{ Wheat } \\
\hline Strain & 3 & 48.280 & $13.803^{* * *}$ \\
\hline$*_{\mathrm{w}}$ & 3 & 1140.615 & $58.490^{* * * *}$ \\
\hline Temperature & 4 & 214.703 & $10.322^{* * *}$ \\
\hline Strain $\mathrm{x} *$ *, & 9 & 5.599 & $2.547^{*}$ \\
\hline Strain $x$ temperature & 12 & 3.498 & 1.591 \\
\hline${ }^{\wedge} \mathrm{W} \times \mathrm{x}$ temperature & 12 & 19.501 & $8.872^{* * *}$ \\
\hline Strain $\mathrm{x} *, \mathrm{x}$ temperature & 36 & 2.198 & $10.758^{* * *}$ \\
\hline \multicolumn{4}{|l|}{ EQU9 } \\
\hline Substrate & 1 & 1.380 & 0.848 \\
\hline${ }^{2} w_{\mathrm{w}}$ & 3 & 711.631 & $61.060 * * *$ \\
\hline Temperature & 4 & 113.687 & $9.169 * * *$ \\
\hline Substrate $\mathrm{x} *$, & 3 & 0.589 & 0.667 \\
\hline Substrate $\mathrm{x}$ temperature & 4 & 1.627 & 1.843 \\
\hline${ }^{\wedge} \mathrm{W} \times \mathrm{x}$ temperature & 12 & 11.655 & $13.202 * * *$ \\
\hline Substrate $\mathrm{x} * P, \mathrm{x}$ temperature & 12 & 0.883 & $10.122 * * *$ \\
\hline
\end{tabular}

* Significant at $P<0.05$

;** Significant at $P<0.01$.

**** Significant at $P<0.001$

* Snedecor's F-test

their significance for the predicted scenarios of climatic change in this and similar regions.

\section{Material and methods}

\subsection{Fungal strains}

F. equiseti $\mathrm{EQU} 5$ and $\mathrm{EQU} 7$ strains were isolated from barley fields in Albacete (Spain) (Marin et al., 2012) and F. equiseti EQU9 and EQU10 strains were isolated from durum wheat fields in Huelva and Sevilla (Spain), respectively (Jurado et al., 2006). All four strains were able to produce trichothecenes and their toxin profiles are described elsewhere (Marin et al., 2012). Fungal cultures were maintained on potato dextrose agar medium (Scharlau Chemie, Barcelona, Spain) at $4{ }^{\circ} \mathrm{C}$ and stored as spore suspensions in $15 \%$ glycerol at $-80{ }^{\circ} \mathrm{C}$ in the Department of Genetics of the Complutense University of Madrid (UCM).

\subsection{Primer design and PCR amplification}

TRI5 specific primer pairs for $F$. equiseti were designed on the basis of a wide alignment using TRI5 sequences retrieved for data bases off. equiseti (GQ865563; Proctor et al., 2009) and the main trichothecene-producing species of Fusarium associated with cereals and related to F. equiseti. The software Primer Express ${ }^{\circledR}$ (Applied Biosystems, Foster City, CA) was used to design the suitable primers for real time RT-PCR assays. The alignment was performed by Clustal method using Bioedit Sequence Alignment Editor v 7.0.9.0 (Hall, 1999) and the following TRI5 sequences: F. graminearum (AY102605, AY102603 and AY102599), $F$. austroamericanum (AY102588), $F$. meridionale (AY102586), F. boothii: AY102595; F. mesoamericanum: AY102598; F acacia-meamsii: AY102578; F. asiaticum: AY102570; F. cortaderiae: AY102601; F. pseudograminearum: AY102585 and AY102583;
F. culmorum: AY102602, AY102571 and AY130291; F. poae: AY130294; F sporotrichioides: AF364179, AY130293 and AY032745; F. langsethiae: JF9662559 and AF449793; F. scirpi: GQ915553; F. semitectum: GQ915550; F. camptoceras: GQ915545). The selected primer pair was: TRI5EQPQ-PF (5' AAGATC CCCAGGTGATGGAAA 3') and TRI5EQPQPR (5' TGACGTAGCCGTGCATGAAG 3'). The specificity of these primers was assessed with genomic D NA from a number ofiF. equiseti strains and related trichothecene-producing and non-producing Fusarium species. Al F. equiseti strains amplified the expected 51 bp band. No amplification product was observed with DNA from other Fusarium strain tested (data not shown).

The amplification reactions were performed in volumes of $25 \mathrm{uL}$ containing $100 \mathrm{ng}$ of template D NA in $3 \mathrm{uL}, 1.25 \mathrm{uL}$ of each primer $(20 \mathrm{uM}), 0.2 \mathrm{uL}$ of Taq polymerase $(5 \mathrm{U} / \mathrm{uL}), 2.5, \mathrm{uL}$ of $1 \mathrm{Ox}$ PCR buffer, $1_{\mathrm{i}} \mathrm{uLofMgCI} \mathrm{I}_{2}(50 \mathrm{mM})$ and 0.25 , $\mathrm{uL}$ of dNTPs $(100 \mathrm{mM})$ (Ecogen, Barcelona, Spain). PCR was performed in a thermocycler (Eppendorf Mastercycler Gradient, Eppendorf, Hamburg, Germany). Amplification products were detected by electrophoresis on $2.5 \%$ agarose ethidium bromide gels in $40 \mathrm{mM}$ Tris-acetate and $1.0 \mathrm{mM}$ EDTA $\mathrm{lx}$ buffer. The amplification protocol for both pairs of primers was: 1 cycle of $120 \mathrm{~s}$ at $94{ }^{\circ} \mathrm{C}, 35$ cycles of $35 \mathrm{~s}$ at $94{ }^{\circ} \mathrm{C}$ (denaturation), $30 \mathrm{~s}$ at $64{ }^{\circ} \mathrm{C}$ (annealing), $30 \mathrm{~s}$ at $72{ }^{\circ} \mathrm{C}$ (extension), and 1 cycle of $10 \mathrm{~min}$ at $72{ }^{\circ} \mathrm{C}$

The TUB2 gene was used as endogenous control gene to normalize the results of real time RT-PCR experiments. The pair of primers used and the amplification protocol was reported previously elsewhere (Marin et al., 2010a) and their sequences were as follows: TUB2PQ-PF (5' CCGAGGCCCAGTCCAACT 3') and TUB2PQ-PR (5' GGCGTCTTGGTA TTGCTGGTA3').

\subsection{Growth in relation to water potential on barley and wheat extract media}

The medium used in this study was a $3 \%(\mathrm{w} / \mathrm{v})$ either barley or wheat extract agar (Ramos et al., 1998). Both cereals extract agar media were made by boiling milled wheat or barley grain in $1 \mathrm{~L}$ of water for $30 \mathrm{~min}$. The resulting mixture was filtered through a double layer of muslin and the volume was made up to $1 \mathrm{~L}$ Subsequently, $20 \mathrm{~g} / \mathrm{L}$ of bacteriological agar (Pronadisa, Madrid, Spain) was added.

This cereal medium was modified with the non-ionic solute glycerol to obtain the water potentials $\left({ }_{w}\right)$ of $-2.8,-7.0$ and - 9.8 MPa corresponding to water activities $\left(\mathrm{a}_{\mathrm{w}}\right)$ of $0.98,0.95$ and 0.93 respectively. The control medium had a water potential of $-0.7 \mathrm{MPa}\left(=0.995 \mathrm{a}_{\mathrm{w}}\right)$. Glycerol modified and un-modified media were prepared with both barley and wheat extracts. Al agar media (in $9 \mathrm{~cm}$ Petri plates) were overlaid with sterile cellophane sheets (NatureFlex ${ }^{\mathrm{TM}} 28 \mathrm{NP}$, Novocel Flexibles SL ., Barcelona, Spain) before inoculation to facilitate removal of the fungal biomass for RNA. extractions.

\subsection{Inoculation, incubation and growth assessment}

A 3-mm-diameter agar disk from the margin of 7-day-old growing colony of each of the four F. equiseti strain grown at $25^{\circ} \mathrm{C}$ was used to centrally inoculate each replicate and treatment. The plates were incubated at $15,20,25,30,35$ and $40{ }^{\circ} \mathrm{C}$ for 10 days. The experiment consisted of at least four replicates per treatment.

Assessments of growth was made daily during the 10-day incubation period. Two diameters of the growing colonies were measured at right angles to each other until the colony reached the edge of the plate. The radii of the colonies were plotted against time and a linear regression was applied to obtain the growth rate $(\mathrm{mm} /$ day) as the slope of the line.

Two dimensional growth rate profiles were obtained for each strain in relation to temperature $\mathrm{x}$ water potential treatments with both barley and wheat extracts. 
Table 2

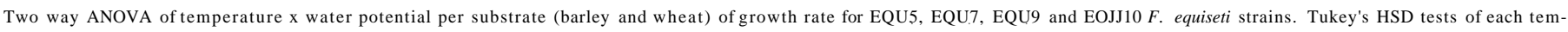
perature and water potential were separately performed. Different letters indicate significant differences at $\mathrm{P}<0.05$.

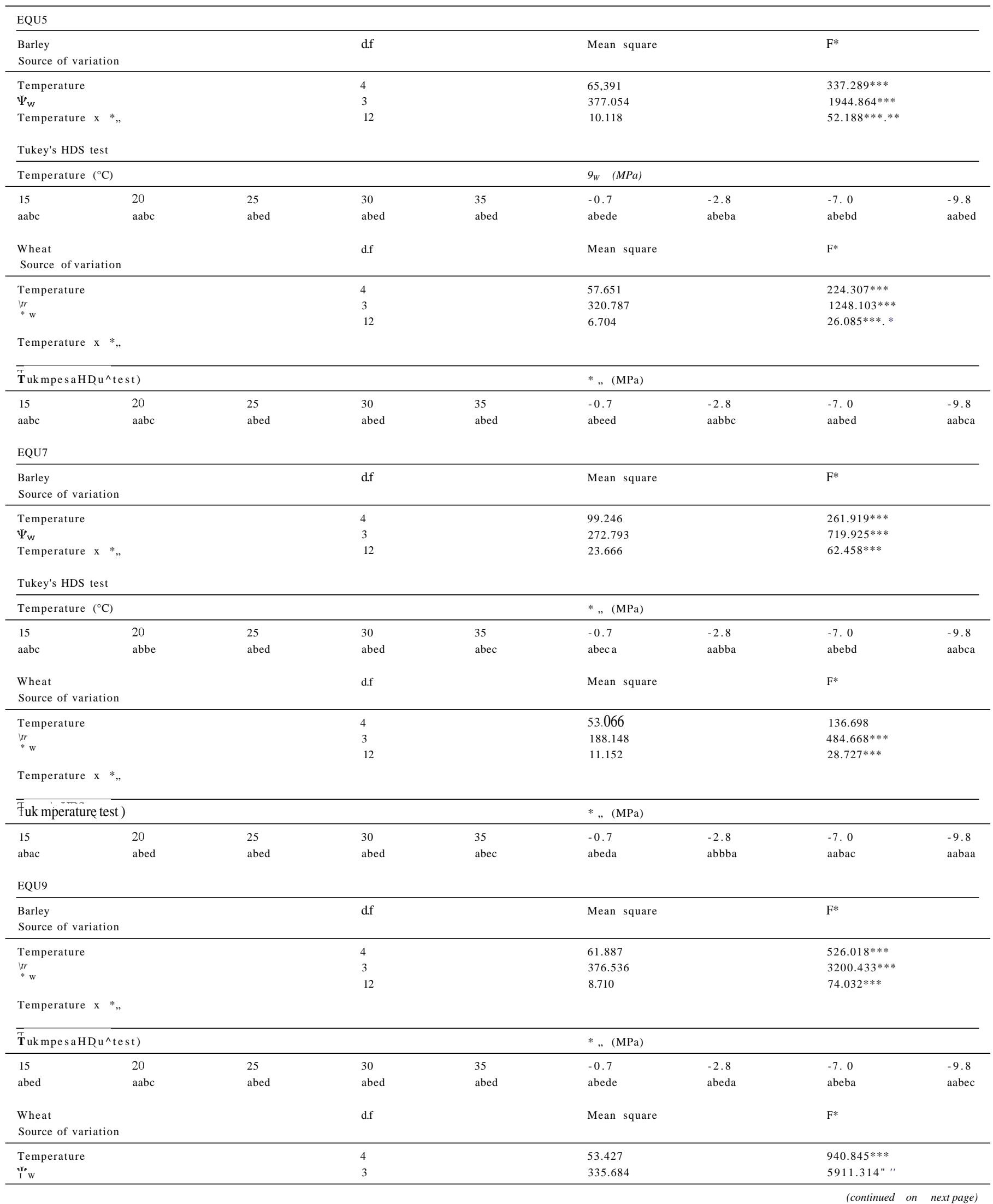




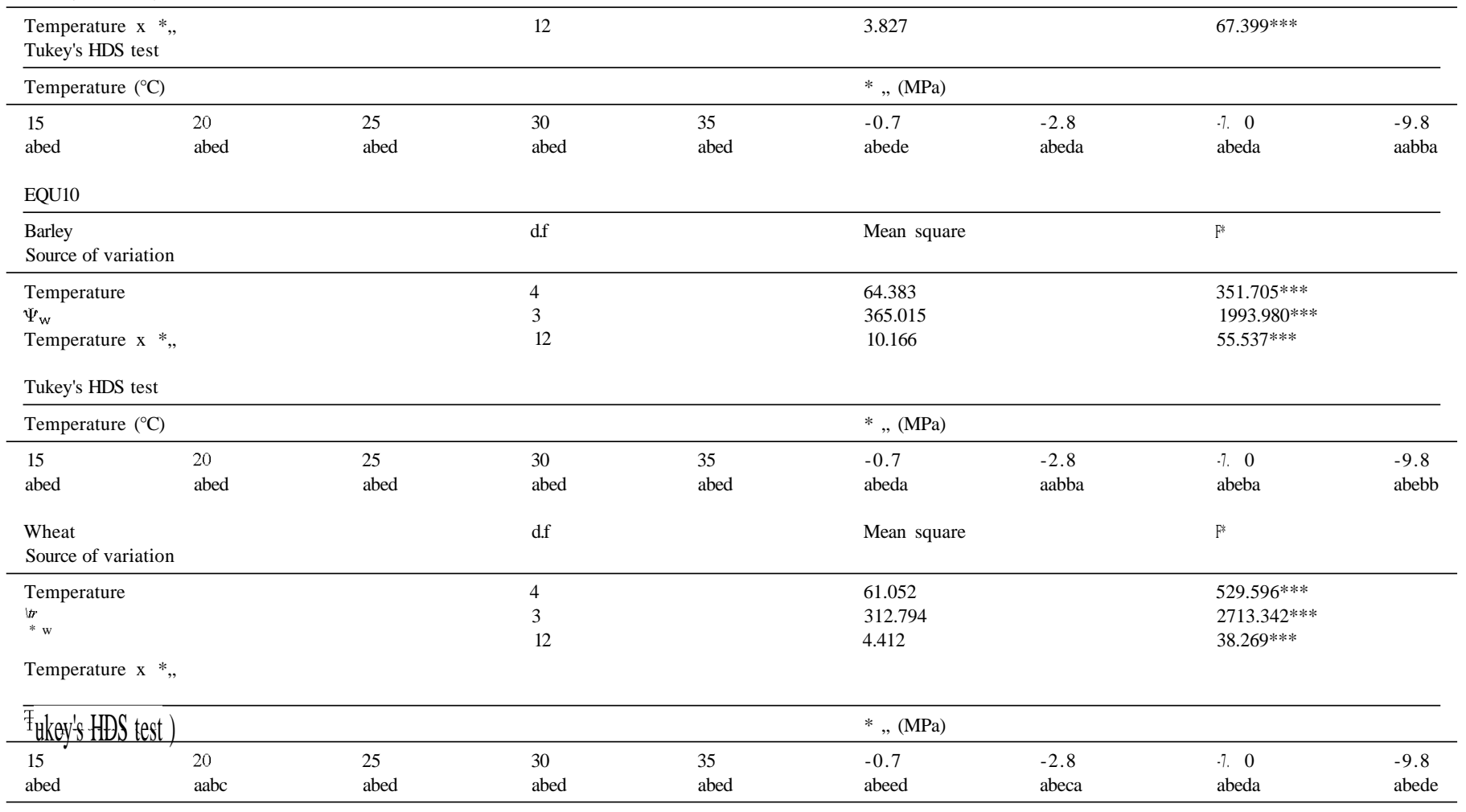

*** Significant at $P<0.001$.

* Snedecor's F-test

\section{RNA isolation and cDNA synthesis}

The biomass of each plate was removed from the cellophane at the end of the incubation period, and the total RNA was extracted using both the "RNeasy® Plant Mini Kit" and "RNeasy® Mini Kit" (Hilden, Germany), according to the manufacturer's instructions, and stored at $-80{ }^{\circ} \mathrm{C}$. First-strand cDNA was synthesized using the "GeneAmp Gold RNA PCR reagent kit" (Applied Biosystems). Each 20 uL reaction mixture contained $500 \mathrm{ng}$ of total RNA $0.5 \mathrm{uLof}$ oligo $(\mathrm{dT})_{16}(50 \mathrm{uM}), 10 \mathrm{uLof} 5 \mathrm{X}$ RT-PCRbuffer, 2 uLof $\mathrm{MgCl}_{2}$ (25 mM), 2 uLofdeoxynucleoside triphosphate (dNTP) $(10 \mathrm{mM}), 2 \mathrm{uL}$ of dithiothreitol $(100 \mathrm{mM}), 0.5 \mathrm{uL}(10 \mathrm{U})$ of RNase inhibitor (20 U/uL), $0.3 \mathrm{uL}$ (15 U) of MultiScribe reverse transcriptase $(50 \mathrm{U} / \mathrm{uL})$, and sterile diethyl pyrocarbonate-treated water up to the final volume. Synthesis of cDNA was performed in a Mastercycler gradient thermal cycler (Eppendorf, Germany) according to the following procedure. After a hybridization step oflOmin at $25^{\circ} \mathrm{C}$, RT was carried out for $12 \mathrm{~min}$ at $42{ }^{\circ} \mathrm{C}$. The cDNA samples were kept at $-20{ }^{\circ} \mathrm{C}$. Samples incubated in the absence of reverse transcriptase were used as controls.

\subsection{Real time RT-PCR and quantitative analysis of the data}

Real time RT-PCR assays were performed to quantify TRI5 and the constitutive TUB2 gene expression in F. equiseti EQU9 strain using both pairs of primers described above. Real time RT-PCR reactions were performed using an ABI PRISM 7900 HT sequence detection system (Applied Biosystems). The PCR thermal cycling conditions for both genes were as follows: an initial step at $95{ }^{\circ} \mathrm{C}$ for $10 \mathrm{~min}$ and 40 cycles at $95{ }^{\circ} \mathrm{C}$ for $15 \mathrm{~s}$ and at $60^{\circ} \mathrm{C}$ for $1 \mathrm{~min}$. SYBR green PCR master mix (Applied Biosystems) was used as the reaction mixture with the addition of $13 \mathrm{uL}$ of sterile Mlli-Q water, $0.6 \mathrm{uL}$ of each primer $(5 \mathrm{uM})$ and $2.5 \mathrm{uLof}$ template cDNA in a final volume of $10 \mathrm{uL}$ In all the experiments, appropriate negative controls containing no template were subjected to the same procedure to exclude or detect any possible contamination or carryover. Each sample was amplified twice in each experiment. Both TRI5 and $T U B 2$ cDNA amplifications were run on the same plate.

The PCR efficiencies for both genes were measured by performing a 10 fold serial dilution of positive control template to generate a standard curve, and by plotting the $\mathrm{C}_{\mathrm{T}}$ as a function of logio of template. The slope in the standard curve for the amplification of the TUB2 gene was - 3.24 while the slope in the standard curve for the amplification of TRI5 was - 3.22. The efficiency of both pairs of primers was 103.57 and $104.61 \%$, respectively and differing less than $10 \%$; thus, within the range of optimal efficiency (90-105\%) and the conditions required to quantify the relative gene expression using the 2 ${ }^{\text {AACT }}$ method (Livak and Schmittgen, 2001). Relative quantification (ACT) was performed by subtracting the CT of the control gene (TUB2) from the CT of the gene of interest (TRI5). In graphic representations (Fig. 2), we used the average $\mathrm{C}_{\mathrm{T}}$ mean value of the three replicates performed in each experiment, and this was subtracted by the calibrator mean value of the three replicates to obtain the corresponding AACT values. These AACT values were transformed to $\log _{2}$ (due to the doubling function of PCR) to generate the relative expression levels.

\subsection{Statistical analysis of results}

The linear regression of the increase of radius (mm) against time (days) was used to obtain the growth rates ( $\mathrm{mm} /$ day) for all replicates and treatments. Multifactor ANOVA of all the three factors (substrate $\mathrm{x}$ temperature $x$ water potential) and two way ANOVA for each substrate (temperature $\mathrm{x}$ water potential) were performed separately per each $F$. equiseti strain for growth rate and in EQU9 for TRI5 gene expression results, including all the replicates per treatment. Subsequent post hoc analyses (Tukey's HSD test of multiple comparisons) were carried out at a $95 \%$ confidence level. Consistency of $T U B 2 \mathrm{C}_{\mathrm{T}}$ values was evaluated using a one-way ANOVA in all the experiments. The results indicated 
that expression of this gene showed a significant stability and consistency in all of the experiments. All sets of results were evaluated using STATGRAPHCS CENTURION XV. I I (Statistical Graphics Corp., Herndon, VA) and SPSS 17.0.0 (Rel, 2008. Chicago: SPSS Inc). The TRI5 gene expression data used were the ACT values.

\section{Results}

\subsection{Effects of temperature $x$ water potential on growth rate on both barley and wheat extract media}

Fig. 1 shows the bi-dimensional maps of relative growth rate of the four $F$. equiseti strains on barley and wheat in response to water potentials (between -0.7 and $-9.8 \mathrm{MPa}$ ) and to temperatures $\left(15-40{ }^{\circ} \mathrm{C}\right.$ ). Optimal growth was observed at $20-30{ }^{\circ} \mathrm{C}$ and between -0.7 and $-2.8 \mathrm{MPa}$ on both substrates. The highest growth rate was observed generally at $25{ }^{\circ} \mathrm{C}$ at $-0.7 \mathrm{MPa}$ with values of $8-9 \mathrm{~mm} /$ day in barley and $7-8 \mathrm{~mm}$ /day in wheat. No growth was observed at $40{ }^{\circ} \mathrm{C}$, and at $15^{\circ} \mathrm{C}$ if combined with - 9.8 MPa. Tables 1 and 2 show the ANOVA analyses and subsequent Tukey's HSD tests. In both barley and wheat substrates, the effects on growth rate of single factors (strains, water potential and temperature) and their interaction were significant. Two-factor interaction between water potential and temperature was also significant. Subsequent separate analyses on each strain revealed significant effects of water potential and temperature (and the threefactor interaction) but not of substrate or the interaction where this factor was participating and were similar in all four isolates (Table 1 only shows only the results of three-factor ANOVA for EQU9). The subsequent separate two-factor ANOVA and Tukey's HSD tests include the results of all the strains and showed quite similar patterns among strains and for both barley and wheat based substrates (Table 2). A comparison of the effect of high temperatures $\left(30-35^{\circ} \mathrm{C}\right.$ ) in combination with water potentials on strains of common Fusarium species in cereals in similar in vitro experiments is summarized in Table 4.

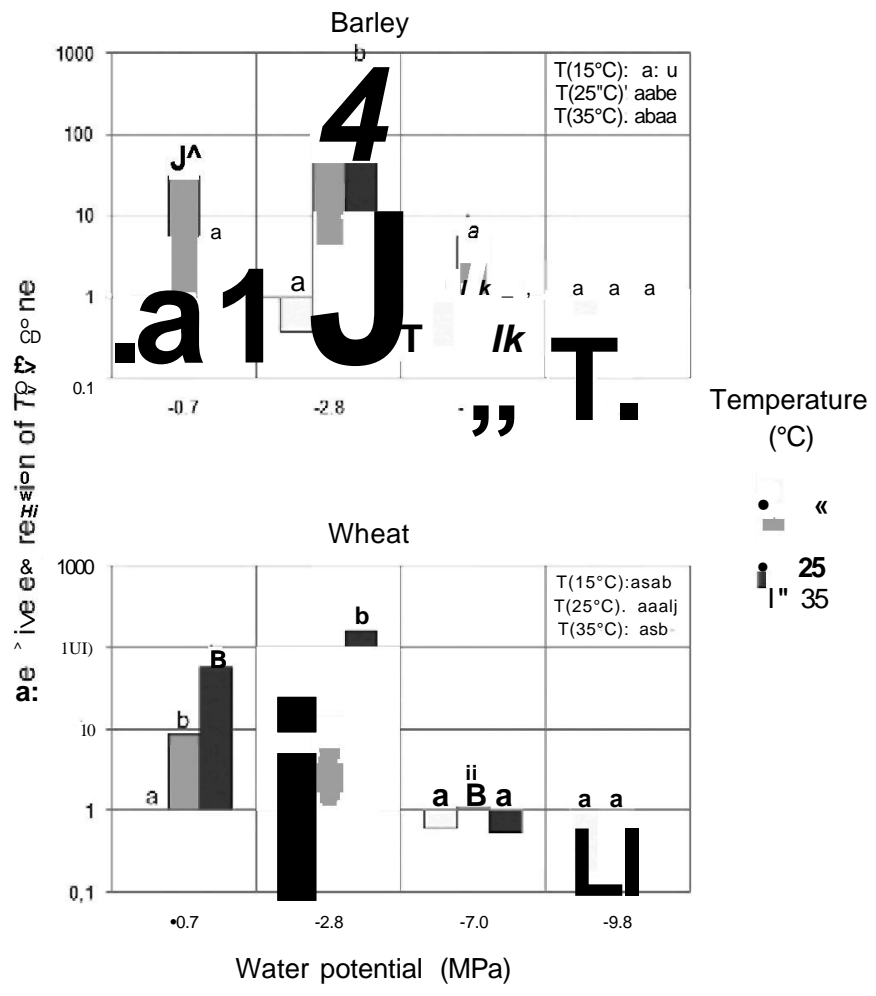

Fig. 2. Relative gene expression pattern of F. equiseti strain EQU9 cultured for 10 days in response to temperature and water potential.

\subsection{Effects of temperature $x$ water potential on TR15 gene expression on both barley and wheat extract media}

Fig. 2 shows the relative gene expression pattern off. equiseti strain EQU9 cultured for 10 days in response to temperature $\left(15,25\right.$ and $\left.35{ }^{\circ} \mathrm{C}\right)$ and water potential $(-0.7,-2.8,-7.0$ and $-9.8 \mathrm{MPa})$ grown on either barley or wheat based medium. Table 3 shows the multifactor ANOVA (substrate $/{ }^{\wedge} \mathrm{W} /$ temperature) and subsequent Tukey's HSD tests performed. Two way ANOVA $\left({ }^{\wedge} \mathrm{W} /\right.$ temperature $)$ were significant $(\mathrm{P}<$ 0.001 ) for single factors and their interaction both in wheat and barley (data not shown). The general gene expression pattern looked like quite similar in both media. However, all single factors considered, the interaction temperature-solute potential and the interaction among the three factors, showed significant differences. Induction of TRIS expression was detected between 25 and $35{ }^{\circ} \mathrm{C}$ and -0.7 and $-2.8 \mathrm{MPa}$ (also at $-7.0 \mathrm{MPa}$ in barley), with maximum values at $35{ }^{\circ} \mathrm{C}$ and $-2.8 \mathrm{MPa}$ in both media.

The standard error of the mean values of the two amplifications performed for each sample in the same plate was less than $0.1 \%$, indicating that the real time RT-PCR assay showed high reproducibility.

\section{Discussion}

This work describes the ecophysiological patterns of 4 strains isolated from cereals grown in Spain belonging to a recently identified population within the so-called $F$. incamatum- $F$. equiseti species complex (ODonnell et al., 2009). The conditions tested considered high temperatures and low water potentials to account the most extreme scenarios among those predicted for Spain. The results obtained in this study indicated that although significant variability among strains was detected, the general growth pattern was similar. This pattern indicated a wide range of permissive conditions of temperature $\left(15-35{ }^{\circ} \mathrm{C}\right)$ and optimal values from 20 to $30{ }^{\circ} \mathrm{C}$. No growth was observed at $40{ }^{\circ} \mathrm{C}$. In the case of water potential, growth was severely decreased at $-9.8 \mathrm{MPa}$ when it was combined with 15 or $40{ }^{\circ} \mathrm{C}$ and optimal growth was detected between -0.7 and $-2.8 \mathrm{MPa}$. This ecophysiological pattern agreed with the wide distribution throughout different agroclimatic regions within Spain. Although no similar studies have been reported to our knowledge on $F$. equiseti from Northern Europe, it might be reasonable to expect that these strains should perform better at lower temperatures and higher water potentials. Taking together the phylogenetic data, toxin and ecophysiological profiles, we suggest that this population might have been genetically isolated for a long time, enough to become well adapted to the environmental conditions of the agroclimatic regions where it is more frequent (Jurado etal., 2006; Marin, 2010; Marin et al., 2012; Soldevilla et al., 2005). The extent of the region where this

Table 3

Multifactorial ANOVA of the relative TPJ5 gene expression of EQU9 F. equiseti strain incubated with two substrates (barley or wheat) for 10 days at different temperatures $(15,25$ and $35{ }^{\circ} \mathrm{C}$ ) and water potentials ( $-0.7,-2.8,-7.0$ and $\left.-9.8 \mathrm{MPa}\right)$.

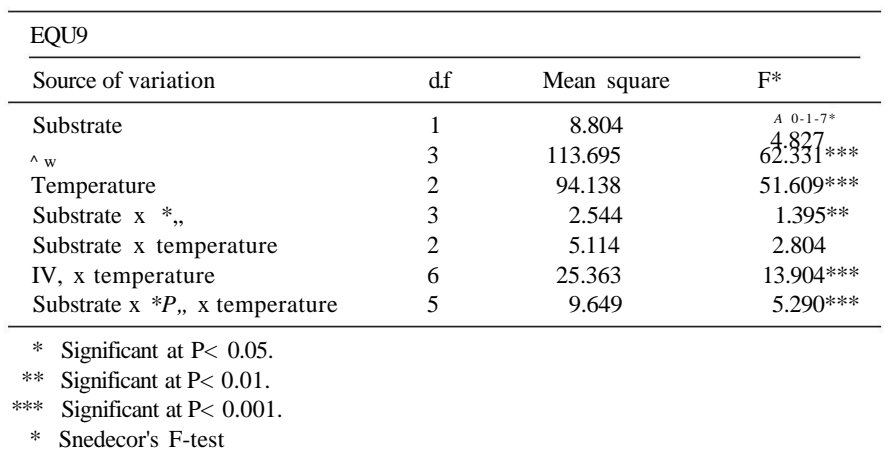


Changes in growth rate by Fusarium species under different temperatures and water potentials.

\begin{tabular}{|c|c|c|c|c|c|c|c|c|c|}
\hline & \multirow[t]{3}{*}{ Maximum growth rate conditions } & \multicolumn{8}{|c|}{ Percentage of reduction on growth rate compared to maximum } \\
\hline & & \multicolumn{4}{|l|}{$30^{\circ} \mathrm{C}$} & \multicolumn{4}{|l|}{$35^{\circ} \mathrm{C}$} \\
\hline & & $-0.7 \mathrm{MPa}$ & $-2.8 \mathrm{MPa}$ & $-7.0 \mathrm{MPa}$ & $-9.8 \mathrm{MPa}$ & $-0.7 \mathrm{MPa}$ & $-2.8 \mathrm{MPa}$ & $-7.0 \mathrm{MPa}$ & $-9.8 \mathrm{MPa}$ \\
\hline F. verticillioides & $0.995,25 X$ & 7.48 & 2.23 & 50.65 & 100 & 30.58 & 17 & 55.68 & 100 \\
\hline F. proliferatum & $0.98,25 X$ & 16.75 & 12.45 & 50.27 & 100 & 33.71 & 16.09 & 58.19 & 100 \\
\hline F. graminearum & $0.98,25 X$ & 51.15 & 47.62 & 82.10 & 100 & 93.75 & 83.33 & 93.02 & 100 \\
\hline F. equiseti (wheat) & $0.995,25 X$ & 10.09 & 26.56 & 64.5 & 88.38 & 56.32 & 50.83 & 79.82 & 100 \\
\hline F. equiseti (barley) & $0.995,25 X$ & 21.95 & 33.03 & 72.96 & 94.34 & 59.50 & 55.20 & 79.52 & 94.68 \\
\hline
\end{tabular}

population might be prevalent is not yet fully determined but strains from Italy and France are included in this group (Marin et al., 2012).

The influence of the substrate or host on colonization or ability to grow by $F$. equiseti has been acknowledged by several authors (Llorens et al., 2004; Marin et al., 2004; Ramirez et al., 2006). Higher levels of fungal contamination of barley than of wheat have been observed (Gil-Serna et al., 2013; Gonzälez-Jaen et al., 2008; Medina et al., 2006; Soldevilla et al., 2005). Differences in growth rate off. equiseti also have been reported among diverse host plant species (Goswami et al., 2008; Palmero etal., 2011). In our case, although growth profiles were similar on barley and wheat media, there were some interesting differences in certain aspects such as absolute maximal growth rate values or counteracting interactions with temperature and water potential. These might be relevant and they will be considered in future studies.

The wide distribution off. equiseti in Spain overlaps to a certain extent with $F$. verticillioides and $F$. proliferatum in some regions and with $F$. graminearum in others (Gonzalez-Jaén et al., 2008; Jurado et al., 2006; Marin, 2010; Marin et al., 2012; Soldevilla et al., 2005). This distribution seems to be consistent with the growth rate patterns of Spanish strains of these species observed in similar in vitro studies (Jurado et al., 2006; Marin et al., 2010a, 2010b, 2012). These data, compared in Table 4, highlight the impact on growth rate that might be expected in future conditions of higher temperatures and more frequent/long drought periods predicted by climatic change scenarios for Spain and other Mediterranean regions. The results suggest that $F$. equiset $i$ would show an intermediate pattern between $F$. verticillioides/ $F$. proliferatum and the less tolerant $F$. graminearum, particularly at moderate/low water potential and $35{ }^{\circ} \mathrm{C}$ The limit between these two regions might depend on the weather conditions of particular years or cultural practices (for instance, irrigation or not). Interactions of these factors with an increase of $2 \mathrm{x}$ and $3 \mathrm{x} \mathrm{CO}_{2}$ above existing levels which may be produced by climate change should also be taken into account (Magan etal., 2011).

Environmental conditions also showed a significant effect on TRI5 mRNA synthesis producing a pattern distinct from that obtained from growth rate analyses. TRI5 gene expression was highly induced between 25 and $35^{\circ} \mathrm{C}$ and -0.7 and $-2.8 \mathrm{MPa}$ water potential on both barley and wheat media. Lower, but still significant, induction was also observed at - 7.0 $\mathrm{MPa}\left(25-35^{\circ} \mathrm{C}\right)$ in barley medium. Interestingly this range includes the optimal conditions for growth, particularly at $25{ }^{\circ} \mathrm{C}$ and between -0.7 and $-2.8 \mathrm{MPa}$, suggesting that trichothecene biosynthesis may occur within the range of conditions most favorable for successful colonization. Even at $35^{\circ} \mathrm{C}$ and $-2.8 \mathrm{MPa}$, the $F$. equiseti strains were able to grow around 3-4 $\mathrm{mm} /$ day average, indicating a high level of constant trichothecene production in conditions considered stressing for most Fusarium species. This pattern contrasted with that TRI5 by F. graminearum (Marin et al., 2010a). A similar situation was observed when expression patterns of the FUMl gene (key gene of fumonisin biosynthesis) produced by $F$. verticillioides and $F$. proliferatum were compared (Marin et al., 2010b). These differences of regulation of mycotoxin biosynthesis, even for the same toxin, by fungal species might contribute to improving their differential adaptation to different environments (or hosts) as well as to environmental changes during their life cycle (Marin et al., 2012). F. equiseti might represent the highest risk for toxin contamination at moderate/low water potential and $30-35{ }^{\circ} \mathrm{C}$

In conclusion, this species might be expected to continue playing a role in future scenarios and contributing to toxin risk. Additionally, the study suggested that substrate/host/cultivar may influence toxin production by direct regulation of toxin biosynthesis independently of fungal growth. The results and the in vitro approach described in this work could be useful in control and breeding strategies to reduce mycotoxin contamination on cereals.

\section{Acknowledgments}

This work was supported by the Spanish MINECO (AGL201022182-C04-01).

\section{References}

Adejumo, T.O., Hettwer, U, Karlovsky, P., 2007. Occurrence of Fusarium species and trichothecene in Nigerian maize. Int J. Food Microbiol. 166,350-357.

Balmas, V, Migheli, Q, Schern, B, Garau, P., O'Donnell, KC, Ceccherelli, G, Kang, S., Geiser, D., 2010. Multilocus phylogenetics show high levels of endemic fusaria inhabiting Sardinian soils (Tyrrhenian Islands). Mycologia 102,803-812.

Brown, D.W., McCormick, S.P., Alexander, N.J., Proctor, R.H., Desjardins, A.E., 2001. A genetic and biochemical approach to study trichothecene diversity in Fusarium sporotrichioides and Fusarium graminearum. Fungal Genet Biol. 32,121-133.

Castellá, G, Cabanes, F.J, 2014. Phylogenetic diversity of Fusarium incamatum-equiseti species complex isolated from Spanish wheat Antonie Van Leeuwenhoek 106,309-317.

Doohan, F.M, Weston, G, Rezanoor, H.N, Parry, D.W, Nicholson, P, 1999. Development and use of a reverse transcriptional-PCR assay to study expression of tri5 by Fusarium species in vitro and in planta. Appl. Environ. Microbiol. 65, 3850-3854.

Foroud, N.A., Eudes, F, 2009. Trichothecenes in cereals grains. Int. J. Mol. Sci. 10,147-173.

Gil-Serna, J, Mateo, E.M, Gonzảlez-Jaén, M.T, Jiménez, M, Vảzquez, C, Patino, B, 2013. Contamination of barley seeds with Fusarium species and their toxins in Spain: an integrated approach. Food Addit Contam. Part A 30, 372-380.

González-Jaén, M.T, Marin, P, González-Salgado, A, Vázquez, C, Aparicio, N, Patino, B, Fernăndez-Hevia, C, Esteban, M, 2008. Detection de especies fungicas productoras de toxinas en cereales espafioles. Utilidad de los métodos basados en el ADN para predetir el riesgo de micotoxinas en cereales. Innovatión y Tecnologia Agroalimentaria 3, pp. 36-43.

Goswami, R.S, Dong, Y, Punja, Z.K, 2008. Host range and mycotoxin production by Fusarium equiseti isolates originating from ginseng fields. Can. J. Plant Pathol. 30, $155-160$.

Hall, TA, 1999. BioEdit: a user-friendly biological sequence alignment editor and analysis program for Windows 95/98/NT. Nucleic Adds Symp. Ser. 41, 95-98

Jurado, M, Vâzquez, C, Callejas, C, González-Jaén, M.T, 2006. Occurrence and variability of mycotoxigenic Fusarium species associated to wheat and maize in the South of Spain. Mycotoxin Res. 22, 87-91.

Jurado, M, Marin, P, Magan, N, Gónzalez-Jaén, M.T, 2008. Relationship between solute and matric potential stress, temperature, growth and FUMl gene expression in two Fusarium verticillioides strains from Spain. Appl. Environ. Microbiol. 74,2032-2036

Jurado, M, Marin, P, Callejas, C, Moretti, A, Vâzquez, C, González-Jaén, M.T, 2010. Genetic variability and fumonisin production by Fusarium proliferatum. Food Mcrobiol. 27,50-57.

Kosiak B, Thorp, M, Skjere, E, Thrane, U, 2003. The prevalence and distribution of Fusarium species in Norwegian cereals: a survey. Acta Agric. Scand. Sect. B Soil Plant Sci. 53,168-176.

Kosiak E.B, Hoist-Jensen, A, Rundberget, T, González-Jaén, M.T, Torp, M, 2005 Morphological, chemical and molecular differentiation of Fusarium equiseti isolated from Norwegian cereals. Int. J. Food Microbiol. 99,195-206.

Leslie, J.F, Summerell, BA, 2006. The Fusarium Laboratory Manual, first ed. Blackwell Publishing, Iowa, USA

Livak K.J, Schmittgen, T.D, 2001. Analysis of relative gene expression data using realtime quantitative PCR and the 2_ AACT method. Methods 25,402-408. 
Llorens, A, Mateo, R, Hinojo, MJ., Valle-Algarra, F.M, Jiménez, M, 2004. Influence of environmental factors on the biosynthesis of type B trichothecenes by isolates of Fusarium spp. from Spanish crops. Int. J. Food Microbiol. 94,43-54.

Logrieco, A, Bottalico, A, Mulé, G., Moretti, A, Perrone, G., 2003. Epidemiology of toxigenic fungi and their associated mycotoxins for some Mediterranean crops. Eur. J. Plant Pathol. 109,647-655.

Lopez-Errasquin, E, Vázquez, C, Jiménez, M, Gónzalez-Jaeń, MT ., 2007. Real time RT-PCR assay to quantify the expression of FUM1 and FUM19 genes from the fumonisinproducing Fusarium verticillioides. J. Microbiol. Methods 68, 312-317.

Maciá-Vicente, J.G, Rosso, LC, Cianco, A, Jansson, H.-B., Lopez-Iiorca, LV, 2009. Colonisation of barley roots by endophytic Fusarium equiseti and Pochonia chlamydosporia: effects on plant growth and disease. Ann. Appl. Biol. 155, 391-401.

Magan, N, Medina, A, Aldred, D., 2011. Possible climate-change effects on mycotoxin contamination of food crops pre- and postharvest Plant Pathol. 60,150-163.

Marin, P., 2010. Añalisis de factores ecofisiológicos que influyen en la expresión de genes relacionados con la biosintesis de toxinas en especies de Fusarium. 978-84-693-5991^1.

Marin, S., Magan, N, Ramos, AJ., Sanchis, V., 2004. Fumonisin-producing strains of Fusarium: a review of their ecophysiology. J. Food Prot. 67,1792-1805.

Marin, P., Jurado, M, Magan, N, Vazquez, C, Gonźalez-Jaén, MX, 2010a. Effect of solute stress and temperature on growth rate and TRI5 gene expression using real time RTPCR in Fusarium graminearum from Spanish wheat Int J. Food Microbiol. 140,169-174

Marin, P., Magan, N, Vazquez, C, Gonźalez-Jaén, MT., 2010b. Differential effect of environmental conditions on the growth and regulation of the fumonisin biosynthetuc gene FUM1 in the maize pathogens and fumonisin producers Fusarium verticillioides and Fusarium proliferatum. FEMS Microbiol. Ecol. 73,303-311.

Marin, P., Moretti, A, Ritieni, A, Jurado, M, Vàzquez, C, González-Jaén, MT, 2012. Phylogenetic analyses and toxigenic profiles of Fusarium equiseti and Fusarium acuminatum isolated from cereals from Southern Europe. Food Microbiol. 31,229-237.

Medina, A, Valle-Algarra, F.M., Mateo, R, Gimeno-Adelantado, J.V., Mateo, F, Jiménez, M, 2006. Survey of the mycobiota of Spanish malting barley and evaluation of the mycotoxin producing potential of species of Altemaria, Aspergillus and Fusarium. Int J. Food Microbiol. 108,196-203.

O'Donnell, K, Sutton, DA, Rinaldi, MG, Gueidan, C, Crous, OW, Geiser, DM., 2009. Novel multilocus sequence typing scheme reveals high genetic diversity of human pathogenic members of the Fusarium incarnatum- F. equiseti and F. chlamydosporum species complexes within the United States. J. Clin. Microbiol. 47,3851-3861.

O'Donnell, K, Humber, RA, Geiser, DM., Kang, S., Park, B., Robert, VARG., Crous, P.W Johnston, P.R, Aoki, T., Rooney, A.P., Rehner, SA, 2012. Phylogenetic diversity of insecticolous fusaria inferred from multilocus DNA sequence data and their molecular identification via FUSARIUM-ID and Fusarium MLST. Mycologia 104, 427-445.

Palmero, D, de Cara, M, Iglesias, C, Gálvez, L, Tello, J.C, 2011. Comparative study of the pathogenicity of seabed isolates of Fusarium equiseti and the effect of the composition of the mineral salt medium and temperature on mycelial growth. Braz. J. Microbiol. 42, 948-953.

Proctor, R.H., McCormick, S.P, Alexander, N.J., Desjardins, A.E., 2009. Evidence that a secondary metabolic biosynthetic gene cluster has grown by gene relocation during evolution of the filamentous fungus Fusarium Mol. Microbiol. 74,1128-1142.

Punja, Z.K, Wan, A, Rahman, M, Goswami, RS., Barasubiye, T., Seifert, KA, Iivesque, C A, 2008. Growth, population dynamics, and diversity of'Fusarium equiseti in ginseng fields. Eur. J. Plant Pathol. 121,173-184.

Ramirez, M.L, Chulze, S., Magan, N, 2006. Temperature and water activity effects on growth and temporal deoxynivalenol production by two Argentinean strains of Fusarium graminearum on irradiated wheat grains. Int J. Food Microbiol. 106,291 -296.

Ramos, AJ, Labernia, N, Marin, S, Sanchis, V, Magan, R, 1998. Effect of water activity and temperature on growth and ochratoxin production by three strains of Aspergillus ochraceus on a barley extract medium and on barley grains. Int. J. Food Microbiol. 44,133-140.

Schmidt-Heydt, M, Parra, R, Geisen, R, Magan, N, 2011. Modelling the relationship between environmental factors, transcriptional genes and deoxynivalenol mycotoxin production by two Fusarium species. J. R Soc. Interface 8,117-120.

Soldevilla, C, Vảzquez, C, Patino, B., Jurado, M, González-Jaén, M.T, 2005. Hongos toxicogénicos asociados a trigos y cebadas de Castilla y Leo'n. Bol. Sanid. Veg. Plagas 31,519-529.

Stepien, L, Gromadzka, K, ChelkowskLJ, 2012. Polymorphism of mycotoxin biosynthetic genes among Fusarium equiseti isolates from Italy and Poland. J. Appl. Genet. 53, 227-236.

Trenholm, H.L, Friend, D, Hamilton, R.M.G, Prelusky, D.B., Foster, B.C., 1989. Lethal toxicity and nonspecific effects. Trichothecene Mycotoxicosis: Pathophysiologic Effects vol. 1. CRC Press, Florida, USA PP-107-142.

Xu, X.M, Nicholson, P, Thomsett, MA, Simpson, D, Cooke, B.M, Doohan, F.M, Brennan, J, Monaghan, S, Moretti, A, Mule, G, Hornok L, Beki, E, Tatnell, J, Ritieni, A, Edwards, S.G, 2008. Relationship between the fungal complex causing Fusarium head blight of wheat and environmental conditions. Phytopathology 98, 69-78. 